\title{
13. Birleşik fiillerin tasnifi ve yapısında birleşik fiil olan birleşik fiiller
}

\section{Hasan KARACA1}

\author{
APA: Karaca, H. (2021). Birleşik fiillerin tasnifi ve yapısında birleşik fiil olan birleşik fiiller. \\ RumeliDE Dil ve Edebiyat Araştırmalar Dergisi, (22), 258-266. DOI: \\ 10.29000/rumelide.890450.
}

\section{Öz}

Türkiye Türkçesinin birçok alanında terim ve sınıflandırma birliği sorunu yaşanmaktadır. Bunlardan birisi de birleşik fiillerin tasnifine dairdir. Konuya dair hemen her kaynak farklı bir birleşik fiil sınıflandırması sunmaktadır. Ayrıca mevcut sınıflandırmalarda bulunmayan yapılar da söz konusudur. Bunlar, bünyesinde birleşik fiil barındıran birleşik fiillerdir. Bu çalışma hem mevcut sınıflandırma farklılıklarını ele almakta hem de şimdiye kadar değinilmemiş dört birleşik fiil yapısını ortaya koymaktadır. Bu dört yapı isim + birleşik fiil $=$ birleşik fiil, fiil + birleşik fiil = birleşik fiil, birleşik fiil + yardımcı fiil = birleşik fiil, birleşik fiil + birleşik fiil = birleşik fiil şeklinde formüle edebileceğimiz fiil öbekleridir. Bunlara kaynaklarda zikredilen isim veya isim işlevli çekimli fiil + yardımcı fiil = birleşik fiil, [fiil + zarf-fiil eki] + yardımcı fiil $=$ birleşik fiil, isim + asıl fiil = birleşik fiil (deyimleşmiş yapılar) yapıları da eklenince toplam yedi başlıktan oluşan bir birleşik fiil tasnifi ortaya çıkmaktadır. Bu tasnif birleşik fiillerin unsurlarını betimleyici bir yaklaşımla tanımlamaya dayanmaktadır. Betimleyici yaklaşımla birleşik fiilleri sınıflandırmak, nesnellik açısından ittifak edilebilecek bir bakış açısı gibi görünmektedir. Türk dili üzerine çalışmalar arttıkça terim ve sınıflandırma birliği sağlama yolundaki farklılıklar da ortadan kalkacaktır.

Anahtar kelimeler: Fiillerin yapısı, birleşik fiil, fiil öbeği, yardımcı fiil, birleşik fiillerin tasnifi

\section{Classification of compound verbs and compound verbs with compound verbs in their structure}

\begin{abstract}
There is a problem of term and classification unity in many areas of Turkish language of Turkey. One of them is related to the classification of compound verbs. Almost every studies on the subject offers a different compound verb classification. There are also structures that are not included in the existing classifications. These are compound verbs that contain compound verbs. In this study, both the existing classification differences have been discussed and four compound verb structures that have not been mentioned so far presented. These four structures are the verb phrases that we can formulate as noun + compound verb = compound verb, verb + compound verb = compound verb, compound verb + auxiliary verb $=$ compound verb, compound verb + compound verb $=$ compound verb. When the noun or, conjugated verb with noun function + auxiliary verb = compound verb, [verb + adverb-verb suffix] + auxiliary verb = compound verb, noun + the main verb $=$ compound verb (idiomatic structures) structures which mentioned in the studies, are added to these, a compound verb classification consisting of a total of seven titles are obtained. This classification is based on defining the elements of compound verbs with a descriptive approach.
\end{abstract}

Dr. Öğr. Üyesi, Gaziantep Üniversitesi, Fen Edebiyat Fakültesi, Türk Dili ve Edebiyatı Bölümü (Gaziantep, Türkiye), hasankaracahk44@gmail.com, ORCID ID: 0ooo-0002-3014-5513 [Araştırma makalesi, Makale kayit tarihi: 23.01.2021kabul tarihi: 20.03.2021; DOI: 10.29000/rumelide.890450]

Adres $\mid$ Address

RumeliDE Dil ve Edebiyat Araşttrmalar Dergisi $\quad$ RumeliDE Journal of Language and Literature Studies Osmanağa Mahallesi, Mürver Çiçeği Sokak, No:14/8 Osmanağa Mahallesi, Mürver Çiçeği Sokak, No:14/8

Kadıköy - İSTANBUL / TÜRKIYE 34714 Kadıköy - ISTANBUL / TURKEY 34714 e-posta: editor@rumelide.com

e-mail: editor@rumelide.com,

tel: +90 5057958124, +90 2167730616 phone: +90 505 7958124, +90 2167730616 
Classifying the compound verbs with the descriptive approach seems like a perspective that can be agreed upon in terms of objectivity. As the studies on the Turkish language increase, the differences in the way of providing terms and classification unity will be also eliminated.

Keywords: structure of verbs, compound verb, verb phrase, auxiliary verb, classification of compound verbs

\section{Giriş}

Bu çalışmada Türkiye Türkçesindeki birleşik fiil sınıflandırmalarından ve kaynaklarda şimdiye kadar değinilmemiş birleşik fiil yapılarından(fark edivermiş ol-, bakıp duruver-, şükredebilir oluverkaybediverip dur- vb.) bahsedilecektir. Birleşik fiiller, eylem karşılayan kelime gruplarıdır. Kelime grupları unsurları olan yapılardır, dolayısıyla birleşik fiiller de unsurlardan oluşmuş söz dizimsel birleşimlerdir. Konuya dair sinıflandırma ve adlandırmalar da bu birleşimin özellikleri üzerinden yapılmaktadır. Ancak Türkiye Türkçesinde birleşik fiiller yapı bakımından bir sınıflandırma birliğine henüz sahip değildir. Kaynaklarda genellikle iki, üç ve dört başlık altında tasnif edilmişlerdir. Bu tasniflerin hemen hepsi farklı bir yaklaşım sergilemektedir. Bire bir örtüşen sınıflandırmaya rastlanmasa da söz konusu farklılıklar temelde derin görüş ayrılıklarına dayanmamaktadır. Daha çok, bilinen yapıları kategorilere ayırmada farklılıklar görülmektedir. Mevcut sınıflandırmaların temelinde şu dört yapı vardır:

a. İsim + yardımcı fiil: kabul et-, dost ol-, sabreyle-vb.

b. fiil + zarf-fiil eki+ yardımcı fiil(tasvir fiilleri): alvver-, bakakal-, sorabil-, düşeyaz- vb.

c. İsim + fiil(deyimleşmiş kalıplar): el aç-, boy at-, kıymet bil- $v b$.

d. fiil(kip ekli/fiil + sıfat-fiil ekli fiil/isim işlevli çekimli fiil) + yardımcı fiil: gidiyor ol-, yapacak ol-, bakmış ol, söylemiş bulun- $v b$. Bu yapının fiil unsurundaki ekin ne eki olduğuna dair de bir görüş birliği yoktur. Bununla ilgili farklı yaklaşımların ne olduğu parantez içinde belirtilmiştir.

Öte yandan birleşik fiillere dair birçok yapıya da kaynaklarda değinilmemiştir. Bunlar, mevcut tasniflere değinildikten sonra ele alınacaktır. Türkiye Türkçesinde yukarıda verilen yapıların tabi tutulduğu belli başlı birleşik fiil sınıflandırmaları şu şekildedir:

\section{Mevcut tasnifler}

\subsection{Birleşik fiilleri ikiye ayıranlar}

\section{Leyla Karahan'ın sınıflandırması:}

A. Bir hareketi karşılayan birleşik fiiller

Ana yardımcı fiillerle kurulan birleşik fiiller: devam et-, dost ol-, karar kıl-, tamamlanmış ol- $v b$.

Diğer fiillerle kurulan birleşik fiiller: yol al-, şehit düş-, el koy- vb.

B. Bir hareketi tasvir eden birleşik filler: koşabil-, yazıver-, gezip dur-vb. (Karahan, 2009: 73-79).

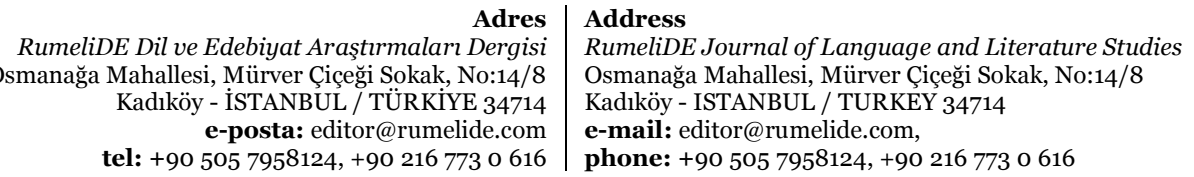


Karahan'ın sınıflandırmasında esas alınan ölçüt, birleşik fiilin hareket karşılaması veya hareket tasvir etmesidir.

\section{H. İbrahim Delice'nin sınıflandırması:}

Delice, birleşik fiil yerine fiil öbeği adlandırmasını daha doğru bulur.

1. Bir yardımcı fiil ile kurulan fiil öbekleri

a. Yabancı isim + yardımcı fiil yapısında: kabul et-, dost ol-, arz et- $v b$.

b. Fiil+zarf-fiil eki+ yardımcı fiil yapısında: yazabil-, kalakal-, sarkıver- gelmiş bulun-, koşup dur-vb.

Delice, bu başlık altında zarf-fiil işlevli eklerle yapılan birleşik fiilleri de verir.

2. Asıl fiil ile kurulan fiil öbekleri: gönül ver-, öne çı-, kol gez- gibi deyimleşmiş yapılar. (Delice, 2012: 24-28)

Delice'nin sınıflanırmasında esas alınan ölçüt, birleşik fiilin asıl fiille mi yardımcı fiille mi kurulduğudur.

\section{Günay Karaağaç’ın sınıflandırması:}

a. İsimlerle yapılan birleşik fiiller

isim + yardımcı fiil: telefon et-, ne eyle-, spor yap- $v b$.

b. Fiillerle yapılan birleşik fiiller

[fiil + zarf-fiil eki] + [yardımcı fiil]: görebil-, kalakal-, toplayıver- vb. (Karaağaç, 2012: 190-195)

Karaağaç, sınıflandırmada birleşik fiilin birinci unsurunun fiil veya isim olmasını esas almıştır.

\section{Muharrem Ergin'in sınıflandırması:}

İsimle birleşik fiil yapan yardımcı fiiller: reddet-, gitmiş ol-, var eyle- $v b$.

fiillebirleşik fiil yapan yardımcı filler: olagel-, gezip dur-, yakalayıver- vb. (Ergin, 2009: 386-389).

Ergin, birleşik fiildeki yardımcı fiilin isimle veya fiille kullanılmasına göre sınıflandırma yapmıştır.

\section{Zeynep Korkmaz'ın sinıflandırması:}

I. Esas anlamını korumuş veya işlev incelikleri kazanmış olan birleşik fiiller

1. Bir yanı ad bir yanı yardımcı fiil olan birleşik fiiller: ifade et-, belli ol-, iltifat eyle- $v b$.

2. Bir yanı sıfat-fiil bir yanı yardımcı fiil olan birleşik fiiller: duymuşol-, sorar ol-, konuşacak ol- $v$ b.

3. Bir yanı zarf-fiil bir yanı fiil olan birleşik fiiller: tasvir filleri: isteyebil-, küçülüver-, süregör- vb.

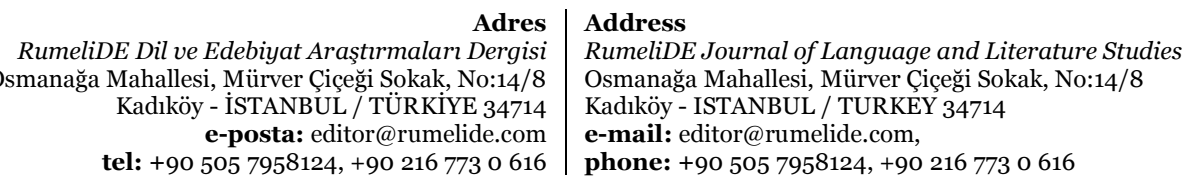


II. Esas anlamını kaybederek deyimleşmiş olan birleşik fiiller

1. Tek ögeli kalıplaşmış birleşik fiiller: suratını as-, kanat ger-, uykusu kaç- vb.

2. İki ögeli kalıplaşmış birleşik fiiller: ağzı laf yap-, eli silah tut-, sözü kısa kes- vb.

3. Üç ögeli kalıplaşmış birleşik fiiller: ayağını yere sağlam bas-, şeytana pabucunu ters giydir- vb.

Deyimlerin yapısı ele alınmıştır.(Korkmaz, 2003: 791- 857)

Korkmaz, ana sınıflandırma ölçütü olarak birleşen fiillerin esas anlamını koruyup korumamasını dikkate almıştır.

\section{Mustafa Özkan ileVeysi Sevinçli’nin sınıflandırması:}

A. İsim + yardımcı fiil = birleşik fiil: görmüş bulun-, idare et-, devral-, görünmez ol- vb.

B. Fiil + zarf-fiil + yardımcı fiil = birleşik fiil: deyiver-, yakabil-, eğlenedur-, esip dur-, çekip git- vb. (Özkan ve Sevinçli, 2017: 66-82)

Özkan ve Sevinçli, birleşik fiilde birleşen unsurların neler oldukları üzerinden bir sınıflandırma yapmıştır.

\subsection{Birleşik fiilleri üçe ayıranlar}

\section{Mehmet Özmen'in sınıflandırması:}

1. İsimlerle kurulan birleşik fiiller: hükmet-, sakin ol-, fiyat biç- $v b$.

2. Fiillerle kurulan birleşik fiiller: yaşayabil-, araştırıp dur-, ısınıver-vb.

3. Çekimli fiillerle kurulan birleşik filler: çekilmiş ol-, gidecek ol-, atar durur vb. (Özmen, 2016: 8798)

Özmen, sınıflandırmada birinci unsurun isim, fiil veya çekimli fiil olmasını dikkate almıştır.

\section{Süer Eker'in sınıflandırması:}

1. Tasvirî (betimsel, deskriptif) eylemler

asıl eylem+zarf-fiil eki+ yardımcı eylem: yazadur-, uyuyakal-, geliver- $v b$.

2. Adla yapılan birleşik eylemler

ad + yardımcı eylem: satın al-, rica et-, yardım et- $v b$.

3. Diğer birleşik eylemler: güleceği gel-, yapmış ol-, ayağa kalkacak ol-vb. (Eker, 2010: 411-412)

Eker, birleşik fiilin tasvir fiili olma, adla kurulmuş olma veya bunların dışında olma durumlarını sınıflandırmaya esas almıştır.

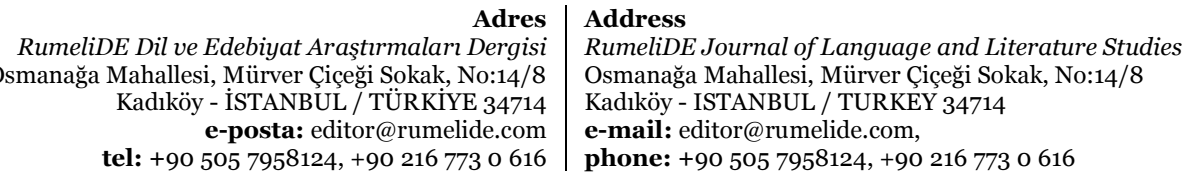




\section{Tahir Nejat Gencan'ın sinıflandırması:}

Kurallı birleşik eylemler: bekleyebil-, atlayıver-, acıyası gel- $v b$.

Öbekleşmiş birleşik eylemler: gönül ver-, dört gözle bekle-, yerinde say- vb.

Yardımcı eylemlerle yapılan birleşik eylemler: hallet-, bağlanmış ol-, düşecek ol-, neşreyle- vb. (Gencan, 2007:358-378)

Gencan, birleşik fiilin tasvir fiili olma, deyimleşmiş fiil olma, yardımcı fiille kurulmuş olma durumlarını tasnife esas almıştır.

\section{Kaya Bilgegil'in sınıflandırması:}

a. Yardımcı fiiller ve onlarla teşkil olunan birleşik fiiller: temenni et-, muhtaç ol-, niyaz eyle- $v b$.

b. İki fiilin birleşmesiyle teşkil olunan birleşik fiiller: bitiriver-, düşeyaz-, yazmaya gör- vb.

c. Kaynatma yoluyla teşkil edilen birleşik fiiller: dil uzat-, yüz sür-, mihnet çek-, yoldan çık- vb. (Bilgegil, 2009: 268-270)

Bilgegil, sınıflandırmasında birleşik fiilin yardımcı fiille kurulmuş olma, asıl fiille kurulmuş olma veya kalıplaşmış olma durumlarını esas almıştır.

\subsection{Birleşik fiilleri dörde ayıranlar}

\section{Özkan, Toker ve Aşçı'nın sınıflandırması:}

1. Asıl yardımcı fiillerle kurulan birleşik fiiller: itiraf et-, mahvol-, işaret et- $v b$.

2. Bir yanı sıfat-fiil bir yanı yardımcı fiil olan birleşik fiiller: karmaşık fiiller: dilimliyor ol-, bakamaz ol, tüküresi gel- $v b$.

3. Bir yanı zarf-fiil bir yanı yardımcı fiil olan birleşik fiiller: sezebil-, dalıp git-, çıkagel- vb.

4. Bir yanı isim bir yanı yardımcı fiil olan birleşik fiiller: el koy-, medet um-, gözü kork-, kaynamaya başla- vb. (Özkan, Toker ve Aşçı, 2016: 76-86).

Özkan, Toker ve Aşçı’nın sınıflandırmasında birleşik fiilin her iki unsurunun yapısal özellikleri esas alınmıştır. Birleşim formülleri üzerinden tasnif yapılmıştır.

\section{Bilal Aktan'ın sinuflandırması:}

1. Bir isim ile yardımcı fiilin birleşmesinden oluşan birleşik filler: mecbur ol-, affet-, kendine gel- $v b$.

2. İsim ile fiil birleşmesinden oluşan (deyimleşmiş) birleşik fiiller: dili tutul-, içine sin-, ders al- $v b$.

3. Bir sıfat-fiil ile yardımcı fiilin birleşmesinden oluşan birleşik filler: unutmuş ol-, tutmaz ol-, düşünecek ol-, beklemiyor ol- $v b$.

\begin{tabular}{r|l} 
Adres & Address \\
RumeliDE Dil ve Edebiyat Araşttrmaları Dergisi & RumeliDE Journal of Language and Literature Studies \\
Osmanağa Mahallesi, Mürver Çiçeği Sokak, No:14/8 & Osmanağa Mahallesi, Mürver Çiçeği Sokak, No:14/8 \\
Kadıköy - ISTANBUL / TÜRKIYE 34714 & Kadıköy - ISTANBUL / TURKEY 34714 \\
e-posta: editor@rumelide.com & e-mail: editor@rumelide.com, \\
phone: +90 505 7958124, +90 2167730616
\end{tabular}


4. Bir fiil ile yardımcı fiilin birleşmesinden oluşan birleşik fiiller(tasvir fiilleri): yürüyüver-, donakal-, biteyaz- vb. (Aktan, 2016: 43-53).

Aktan’ın sınıflandırmasında birleşik fiilde birleşen unsurların neler olduğu ve birleşim formülleri esas alınmıştır.

Görüldüğü üzere sınıflandırmaya tabi tutulan yapılar aynı olmasına rağmen ayrı ayrı tasnifler ortaya çıkmıştır. Söz konusu sınıflandırmalar birleşik fiildeki ilk unsur, ikinci unsur veya her iki unsur dikkate alınarak yapılmıştır. Tasniflerdeki çeşitlilik bu farklı yaklaşımlara dayanmaktadır. Öte yandan kaynaklarda birleşik fiil kavramı, bünyesinde tek yardımcı fiil bulunan veya iki fiilden oluşan bir yapı olarak düşünülmüştür. Bir birleşik fiilin diğer fiiller gibi birleşik fiil bünyesinde görev alabileceği göz ardı edilmiştir. Türkiye Türkçesinde terk ediver-, çözüverecek ol-, bakakalıver -, yardım edecek ol-, kaybediverip dur-, fark eder oluver- gibi bir veya her iki unsuru birleşik fiil olan yapılar da söz konusudur. Bir birleşik fiil, yardımcı fiil veya isim unsuru olarak başka bir birleşik fiilin bünyesinde yer alabilir, yani Türkiye Türkçesinde birleşik fiiller başka birleşik fiillerin kuruluşunda görev alabilir. $\mathrm{Bu}$ konuda Muharrem Ergin, birleşik fiil unsurlarının ikiden fazla olabileceğini belirtmekle yetinmiştir: "Birleşik fiilde yardımcı fiilden önce gelen unsur umumiyetle tek kelime olmakla beraber, bazan bir kelime gurubu da olabilir: ters yüz et-, kayboluver- misallerinde olduğu gibi.” (Ergin, 2009: 389).

Yapı olarak test / et- ile test / ediver-; sabr / eyle- ile sabr / eyleyebil-; baka / kal- ile baka / kalvverisim veya [fiil + zarf-fiil eki] + yardımcı fiil birleşiminden oluştuğuna göre birleşik fiiller, bir başka birleşik fiilin yardımcı fiili olabilmektedir. Standart bilgimiz bize et-, eyle-, ol-, kal-, bulun-, yap-, durörneklerinde olduğu gibi yardımcı fiillerin sınırlı sayıda fiilden oluştuğunu ve bunların da tek sözcük şeklinde olduğunu söylese de bunlarla kurulan birleşik fiillerin yardımcı fiil olarak kullanılabilmesi dil açısından bir aykırılık teşkil etmemektedir. Öte yandan yardım edecek / ol-, şükredip / dur-, kaybetmiş / bulun-gibi yapılarda da birleşik fiilin isim unsuru, birleşik fiildir. Aldıkları ek, kip / sıfatfiil eki olsa da bunlar birleşik fiilin isim unsurunu teşkil etmektedir. Birleşik fiilin hem isim hem yardımcı fiil unsurunun bir birleşik fiil olabilmesi Türkiye Türkçesinde bunların yapısını yeniden gözden geçirmeyi gerektirmektedir.

Kaynaklarda değinilmemiş birleşik fiil yapılarını dört başlık altında vermek mümkündür. Bunlar, birleşik fiillerle kurulmuş birleşik fiillerdir:

1. isim + birleşik fiil $=$ birleşik fiil, 2. fiil + birleşik fiil $=$ birleşik fiil, 3. birleşik fiil + yardımcı fiil $=$ birleşik fiil, 4. birleşik fiil + birleşik fiil = birleşik fiil .

\section{2. Önerilen tasnifler}

\section{1. İsim + birleşik fiil $=$ birleşik fiil}

Bir isim unsuru ile bir yardımcı fiil işlevli birleşik fiil unsurunun birleşmesinden oluşmuştur: nakl / ediver-, arz / olunuver-, hiss / edebil- kayd / edeyaz-, test / edip dur-vb.

Yeni sistemi hemen test edivermiştik.

Üç gün içinde bütün mahsulü naklediverdi.

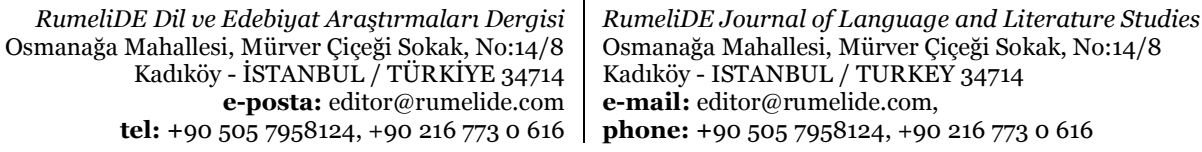


Koca otobüsü sokağa park ediverecekti.

\subsection{Fiil + birleşik fiil $=$ birleşik fiil}

Bu yapı, bir fiil unsuru ile birleşik yardımcı fiilin birleşmesinden oluşmuştur: bakıp / duruver-, çıkmış / olabil-, gider / oluver- $v b$.

Köylüler arkamızdan bakıp duruvermişti.

Çocuklar her gün erkenden kalkar oluverdi.

Planları tutsaydı buralardan gitmiş olabilecekti.

\subsection{Birleşik fiil + yardımcı fiil $=$ birleşik fiil}

Bir birleşik fiil ile yardımcı fiilin birleşmesinden oluşmuş öbektir: sabreder / bul-, dönüp durur / ol-, soruverecek / ol-, anlatabilmiş / ol-, sürüp gider / ol-, şükredebilir / ol- vb. Yapıdaki birleşik fiilin kuruluşunda da başka bir birleşik fiil yer alabilir: park ediverecek / ol-, yardım edivermiş / bulun- vb.

Onu sıkıntıları karşısında her defasında sabreder bulurduk.

Bütün bunları anlatabilmiş olmayı isterdim.

Küçük yaşta gurbette dolaşıp durur olmuştu.

Böylece geminin yükü sevk edilivermiş oldu.

\subsection{Birleșik fiil + birleşik fiil $=$ birleșik fiil .}

Her iki unsuru birleşik fiilden oluşmuş birleşik fiillerdir: sabreder / oluver, kaydeder / oluver, bakıp durur / oluver-, nakletmiş / olabil- vb. Yapının birinci unsurundaki birleşik fiilin kuruluşunda da başka bir birleşik fiil yer alabilir: takip edilebilir olabil-, kaybedilebilir oluver-, hakedebilecek olabil$v b$.

Herkes olan bitene bakıp durur oluvermişti.

Bu saate kadar bütün eşyayı nakletmiş olabilmeliydik

Bu kadarını anlatamamış olamaz.

$\mathrm{O}$ anda her şeyi reddedebilir olabilecek miyiz bilmiyoruz.

Bütün bu yapılara ek olarak daha fazla birleşik fiilin bir araya gelebildiği dilbilgisi ve söz dizimi bakımından doğru, ancak kullanımı olmayan ya da belli şartlarda mümkün olabilecek fark eder oluvermiş ol-, hissedebilir olabilmiş ol-, şükredebiliyor olabilmiş ol- gibi yapılardan da söz edilebilir.

Birleşik fiillerin sınıflandırmasında birleşiğin betimlemesini yapmak ve formülünü ortaya koymak en sağllklı yol olarak görünmektedir. Buna göre Türkiye Türkçesinde birleşen unsurlar üzerinden

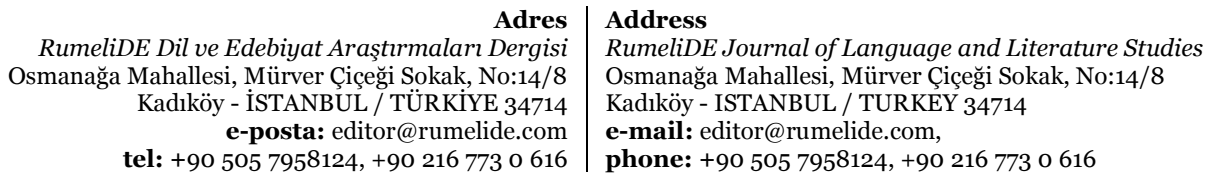


bakıldığında yedi farklı birleşik fiil formülünden bahsetmek mümkündür. Bu maddeleme aynı zamanda birleşik fiil tasnifi önerisidir:

1. İsim veya isim işlevli çekimli fiil + yardımcı fiil = birleşik fiil: zann / et-, kayd / ol-; gider / ol- $v b$.

2. İsim + asıl fiil = birleşik fiil(deyimleşmiş yapılar): kulak / as-, boynunu / bük-, çileden / çık- vb.

3. [Fiil + zarf-fiil eki] + yardımcı fiil = birleşik fiil: alı / ver-, tuta / bil-, akup / dur- vb.

4. İsim + birleşik fiil = birleşik fiil: sarf / ediver-, pişman / olabil-, seyr / edip dur- vb.

5. [fiil + zarf-fiil eki] + birleşik fiil = birleşik fiil: sorup / durabil-, kala / kalabil-, çekip / gidiver-

6. Birleşik fiil(isim işlevli) + yardımcı fiil $=$ birleşik fiil: saklanabiliyor $/ \mathrm{ol}-$, tartıverecek $/ \mathrm{ol}$-, okuyuvermiş / bulun- vb.

7. Birleşik fiil(isim işlevli) + birleşik fiil = birleşik fiil: çevirebilmiş / olabil-, yapabilir / oluver-, tutabiliyor / olabil- $v b$.

\section{Sonuç}

Türkiye Türkçesinde birleşik fiillerin sınıflandırılmasına dair bir birlik söz konusu değildir. Kaynaklarda birbirinden farklı tasnifler yapılmıştır. Ayrıca mevcut sınıflandırmalara dâhil edilmesi gereken birleşik fiillerin tıpkı diğer fiiller gibi birleşik fiil bünyesinde yer alabileceğini örnekleyen birleşimler de söz konusudur. Bunların da dikkate alınmasıyla Türkiye Türkçesinde birleşik fiiller, unsurlarının birleşimi üzerinden tanımlanıp sınıflandırıldığında yedi farklı yapının söz konusu olduğu görülmektedir. Mevcut sınıflandırmalarda esas alınan üç yapı, isim veya isim işlevli çekimli fiil + yardımcı fiil $=$ birleşik fiil, [fiil + zarf-fiil eki] + yardımcı fiil $=$ birleşik fiil, isim + asıl fiil $=$ birleşik fiil(deyimleşmiş yapılar) şeklindedir. Bu çalışmayla sınıflandırmaya dâhil edilmesi önerilen birleşik fiillerin tablosu ise şu şekildedir:

Tablo 1: Kuruluşunda birleşik fiil bulunan birleşik fiiller

\begin{tabular}{|l|l|}
\hline Birleşik fiilin yapısı & Örnekler \\
\hline İsim + birleşik fiil(tasvir fiili) & kaybediver-, şükredebil-, sevk ededur- \\
\hline [fiil + zarf-fiil eki] + birleşik fiil(tasvri fiili) & çekip gidiver,-tekrarlayıp durabil-, şaşakalabil- \\
\hline birleşik fiil + yardımcı fiil & işlenebilir ol-, izah edilebilir ol-, rast gelmiş bulun- \\
\hline birleşik fiil + birleşik fiil & yapabilmiş olabil-, görebilir oluver-, arz edilebilir olabil- \\
\hline
\end{tabular}

$\mathrm{Bu}$ unsurların birtakım anlam incelikleri de ortaya koyduğu muhakkaktır. Ancak, söz konusu yapılara dair anlam incelemesi bu çalışmanın amaç ve sınırlarını aşmaktadır.

Türkiye Türkçesinde birleşik fiillerin yapısını betimlemek suretiyle sınıflandırma başlıkları oluşturmak, üzerinde ittifak edilebilelcek bir tutumdur.

\section{Kaynakça}

Aktan, B. (2016). Türkiye Türkçesinin Söz Dizimi. Konya: Eğitim.

Bilgegil, M. K. (2009). Türkçe Dilbilgisi. Erzurum: Salkımsöğüt.

\begin{tabular}{r|l} 
Adres & Address \\
RumeliDE Dil ve Edebiyat Araşturmaları Dergisi & RumeliDE Journal of Language and Literature Studies \\
Osmanağa Mahallesi, Mürver Çiçeği Sokak, No:14/8 & Osmanağa Mahallesi, Mürver Çiçeği Sokak, No:14/8 \\
Kadıköy - İSTANBUL / TÜRKIYE 34714 & Kadıköy - ISTANBUL / TURKEY 34714 \\
e-posta: editor@rumelide.com & e-mail: editor@rumelide.com, \\
tel: +90 505 7958124, +90 216 773 0 616 & phone: +90 505 7958124, +90 2167730616
\end{tabular}


Delice, H. İ. (2012). Türkçe Sözdizimi. İstanbul: Kitabevi.

Eker, S. (2010). Çă̆daş Türk Dili. Ankara: Grafiker.

Ergin, M. (2009). Türk Dil Bilgisi. İstanbul: Bayrak.

Gencan, T. N. (2007). Dilbilgis. Ankara: Tek Ağaç.

Karaağaç, G. (2012). Türkçenin Söz Dizimi. İstanbul: Kesit.

Karahan, L. (2007). Türkçede Söz Dizimi. Ankara: Akçağ.

Korkmaz, Z. (2003). Türkiye Türkçesi Grameri(Şekil Bilgisi). Ankara. TDK.

Özkan, A., Toker, M., Aşçı, U. D. (2016). Türkiye Türkçesi Söz Dizimi. Konya: Palet.

Özkan, M., Sevinçli, V. (2017). Türkiye Türkçesi Söz Dizimi. İstanbul: Akademik Kitaplar.

Özmen, M. (2016). Türkçenin Sözdizim. Adana: Karahan.

Address

RumeliDE Journal of Language and Literature Studies Osmanağa Mahallesi, Mürver Çiçeği Sokak, No:14/8

Kadıköy - ISTANBUL / TURKEY 34714

e-mail: editor@rumelide.com,

phone: +90 505 7958124, +90 2167730616 